\title{
ATRATIVIDADE E PREFERENCIA ALIMENTAR DE ADULTOS DE Epicauta atomaria (Germ., 1821) (COL.: MELOIDAE) EM MARACUJAZEIROS (Passiflora spp.), SOB CONDIÇÕES DE LABORATÓRIO ${ }^{1}$
}

\author{
EDSON LUIZ LOPES BALDIN² e FERNANDO MESQUITA LARA ${ }^{3}$
}

\begin{abstract}
RESUMO - A atratividade e a preferência alimentar de adultos de Epicauta atomaria (Germ., 1821) por folhas de espécies de maracujazeiro Passiflora spp. foram avaliadas sob condições de laboratório. Em testes de atratividade realizados em placas de Petri e olfatômetro, os discos foliares e extratos foliares de $P$. setacea e $P$. edulis $\mathrm{f}$.flavicarpa foram os mais preferidos por adultos de $E$. atomaria, enquanto $P$. giberti, $P$. nitida e $P$. alata foram os menos preferidas nos dois tipos de recipientes. Nos testes de consumo com e sem chance de escolha utilizando discos foliares, $P$. setacea foi a mais consumida, confirmando sua suscetibilidade; $P$. giberti e $P$. nitida foram pouco consumidas, apresentando não-preferência para alimentação como mecanismo de resistência; $P$. edulis f. flavicarpa e $P$. alata também revelaram não-preferência para alimentação, porém em níveis mais baixos.
\end{abstract}

Termos para indexação: Insecta, Passiflora spp., resistência de plantas.

\section{ATTRACTIVITY AND FEEDING PREFERENCE OF ADULTS OF Epicauta atomaria (Germ., 1821) (COL.: MELOIDAE) IN PASSION FRUIT (Passiflora spp.), UNDER LAB CONDITIONS}

\begin{abstract}
The attractivity and feeding preference of adults of Epicauta atomaria (Germ., 1821) for leaves of passion fruit species Passiflora spp. were evaluated under laboratory conditions. In attractivity tests accomplished in Petri dishes and olfactometer, the leaf disks and leaf extracts of $P$. setacea and $P$. edulis f. flavicarpa were the most preferred by adults of E. atomaria, while P. giberti, $P$. nitida and $P$. alata were the least preferred in the two kinds of recipients. In consumption tests (free and no choice), using leaf disks, $P$. setace $a$ was the most consumed, confirming to be susceptible; $P$. giberti and P. nitida, were the least consumed, expressing feeding nonpreference as resistance mechanism;. P. edulis f. flavicarpa and P. alata also presented feeding nonpreference, however in fewer levels.
\end{abstract}

Index terms: Insecta, Passiflora spp., host plant resistance.

\section{INTRODUÇÃO}

A cultura do maracujazeiro apresenta uma rica fauna formada por ácaros e insetos, sendo alguns extremamente úteis (polinização) e outros altamente nocivos (Santos \& Costa, 1983; Ruggiero et al., 1996; Nascimento, 1997). Boiça Jr. (1998) afirma que praticamente todas as estruturas do maracujazeiro (ramos, folhas, botões florais, flores e frutos) podem ser atacadas por insetos, afetando significativamente a produtividade.

Boaretto et al. (1994) alertam para o surgimento de determinadas espécies de insetos assumindo o "status" de praga e sobrepondo em danos aquelas tradicionalmente relacionadas na literatura como "chaves". Epicauta atomaria (Germ.) não está relacionada entre as principais pragas da cultura do maracujazeiro. Gallo et al. (1988) descrevem E. atomaria como uma praga polífaga, cujo adulto mede cerca de 8 a $17 \mathrm{~mm}$ de comprimento, de coloração geralmente escura, com corpo revestido de pêlos finos e curtos de cor cinza. Em grandes populações, os adultos destroem em pouco tempo as folhas de diversas culturas, deixando apenas as nervuras. Teixeira (1994) cita que este inseto ocasionou grandes danos na década de 80 nas regiões de Campinas e Jaboticabal - SP, atacando Passiflora edulis (Sims) e P. serrato digitata (L.), respectivamente. Danos ocasionados por E. atomaria em leguminosas foram citados por Lourenção et al. (1985), que notaram desfolha entre 17,2\% e 32,0 $\%$ nas plantas de farinha-seca. Estudando outras leguminosas, Nead et al. (1996) constataram que as plantas de tremoço são mais preferidas por Epicauta fabricini (Leconte) que as de feijão, grão-de-bico e lentilha. Boiça Jr. et al. (1996) compararam a preferência alimentar de E. atomaria entre nove espécies de maracujazeiro, constatando maior atratividade e consumo do inseto em folhas de P. caerulea.

Segundo Rossetto et al. (1981) e Lara (1991), o controle de insetos pelo uso de materiais resistentes é o método ideal, principalmente em virtude da preservação ambiental e da sensível redução nos custos de produção. Devido à escassez de trabalhos com este enfoque, desenvolveu-se esta pesquisa com o objetivo de selecionar espécies de maracujazeiro resistentes a $E$. atomaria, através da avaliação de sua preferência alimentar e da atratividade dos materiais.

1 (Trabalho 257/2000). Recebido: 24/11/2000. Aceito para publicação: 18/11/2001.

2 Doutorando do Curso de Entomologia da FFCLRP/USP, Av. Bandeirantes, 3900, Depto. de Biologia, Bloco R, 14040-901, Ribeirão Preto, SP. Bolsista da Fapesp.

3 Professor, FCAV/UNESP, Via de Acesso Prof. Paulo Donato Castellane, s/nº, Depto. de Fitossanidade, 14884-900, Jaboticabal, SP. Bolsista do CNPq. 


\section{MATERIAL E MÉTODOS}

Foram conduzidos no Laboratório de Resistência de Plantas a Insetos, da Faculdade de Ciências Agrárias e Veterinárias, UNESP, Jaboticabal, entre os anos de 1998 e 1999, ensaios de preferência alimentar de adultos de E. atomaria em cinco espécies de maracujazeiro. Todos os insetos foram coletados na cultura da alfafa, evitando o condicionamento préimaginal, citado por Lara (1991), e mantidos em jejum durante 24 horas antes do início dos ensaios.

Ensaios com discos foliares. Foram realizados testes de consumo e atratividade, simultaneamente, utilizando-se de discos foliares das espécies P. alata, P. edulis f. flavicarpa, P. nitida, $P$. setacea e $P$. giberti. Para tanto, retiraram-se dois discos de folhas novas, simetricamente opostos (vazador de 2,54 cm de diâmetro), sendo um deles utilizado como tratamento e outro como testemunha. Utilizaram-se placas de Petri, colocando-se um disco de papel de filtro umedecido ao fundo, sendo os discos dos diferentes genótipos distribuídos ao acaso, em círculo, no interior destas. Liberaram-se 5 adultos por placa. Foram empregadas 10 repetições em delineamento de blocos casualizados. Foram avaliados o consumo dos insetos e o número de indivíduos atraídos pelos discos aos 15; 30; 60; 90; 120 e 180 minutos da liberação. Durante o período de avaliações, as placas de Petri foram mantidas dentro de uma BOD $\left(25 \pm 2^{\circ} \mathrm{C}\right.$ e $65 \pm 10 \%$ UR $)$ e após constatado o consumo entre 80 e $100 \%$ num dos tratamentos, encerrou-se o ensaio. A seguir, os discos utilizados como tratamentos e testemunhas foram pesados, calculando-se o peso consumido pelos insetos em cada tratamento, descontando-se a respectiva percentagem de umidade perdida para o meio. Para o teste de consumo sem chance de escolha, seguiu-se a mesma metodologia descrita nos testes com chance, colocando-se, porém, 1 disco foliar/espécie/placa, juntamente com 2 insetos, seguindo um delineamento inteiramente casualizado. Neste ensaio, não foi avaliada a atratividade dos materiais.

Ensaio com olfatômetro. Para este ensaio, folhas novas de cada espécie (exceto $P$. giberti) foram coletadas no campo, sendo posteriormente lavadas e secas em laboratório. Pesou-se $1 \mathrm{~g}$ de cada folha, colocando-as em seguida dentro de um cadinho de porcelana, juntamente com 5 gotas de água destilada. Este material foi macerado até que fosse obtido o extrato aquoso de cada tratamento. Colocou-se $1 \mathrm{ml}$ de cada extrato em porções de algodão, sendo estas conduzidas para compartimentos do olfatômetro, localizado em outra sala. Os insetos (2/espécie) permaneceram 5 minutos dentro do olfatômetro ligado, sem possibilidade de acesso aos materiais; após este período, foi liberada a passagem para os compartimentos, avaliando-se o número de insetos atraídos a $1 ; 5 ; 15 ; 30 ; 45$ e 60 minutos da liberação. Efetuaram-se 10 repetições em delineamento de blocos casualizados.

Análise Estatística. Os dados foram transformados em $\sqrt{x+0,5}$ e submetidos à análise de variância, sendo as médias comparadas pelo teste de Tukey, ao nível de $5 \%$ de probabilidade.

\section{RESULTADOS E DISCUSSÃO}

Ensaios com Discos Foliares. O consumo médio de discos por adultos de E. atomaria no teste com chance de escolha (Tabela 1) foi maior em $P$. setacea $(31,32 \pm 10,30 \mathrm{mg})$, diferindo significativamente das demais espécies. Embora tenha sido consumida $(2,94 \pm 1,55 \mathrm{mg})$ em reduzida quantidade, $P$. edulis $\mathrm{f}$. flavicarpa não diferiu significativamente de P. alata, P. nitida e $P$. giberti, cujos discos não foram atacados. Em teste de consumo sem chance de escolha (Tabela 1), P. setacea novamente diferiu significativamente das demais espécies; entretanto, neste tipo de ensaio, todos os materiais, com exceção de $P$. nitida, foram consumidos. Estes dados indicam que as folhas de P. giberti e principalmente $P$. nitida são menos preferidas para alimentação pelo inseto em relação às demais espécies, sugerindo a nãopreferência como mecanismo de resistência nestes materiais. Níveis mais baixos de não-preferência para alimentação também foram constatados em P. edulis f. flavicarpa e P. alata. Em ensaio semelhante, Boiça Jr. et al. (1996) também observaram que discos foliares de P. edulis f. flavicarpa, P. alata e P. nitida foram pouco preferidos por $E$. atomaria; entretanto, a espécie $P$. giberti não estava incluída nos testes.

Com relação à atratividade dos discos de folha (Figura 1), P. setacea foi o mais atrativo para o inseto em todos os períodos de avaliação, diferindo significativamente das outras espécies. Com exceção de $P$. edulis f. flavicarpa a 15 e 30 minutos da liberação e $P$. alata a 180 minutos da liberação, que mostraram atração semelhante a $P$. setacea nos demais tempos de avaliação, as espécies $P$. nitida e $P$. giberti foram semelhantes entre si quanto à atratividade foliar.

TABELA 1 - Peso médio ( \#EP) consumido por adultos de Epicauta atomaria em discos foliares de espécies de maracujazeiro.

Consumo (mg)

\begin{tabular}{lll}
\cline { 3 - 3 } Espécies & Com chance de escolha & Sem chance de escolha
\end{tabular}

\begin{tabular}{lcc}
\hline P. setacea & $31,32 \pm 10,30 \mathrm{a}$ & $31,48 \pm 7,51 \mathrm{a}$ \\
$P$. edulis f.flavicarpa & $2,94 \pm 1,55 \mathrm{~b}$ & $2,99 \pm 1,71 \mathrm{~b}$ \\
$P$. alata & $0,00 \pm 0,00 \mathrm{~b}$ & $4,47 \pm 4,01 \mathrm{~b}$ \\
$P$. giberti & $0,00 \pm 0,00 \mathrm{~b}$ & $1,32 \pm 1,07 \mathrm{~b}$ \\
$P$. nitida & $0,00 \pm 0,00 \mathrm{~b}$ & $0,00 \pm 0,00 \mathrm{~b}$ \\
\hline F & $8,98^{*}$ & $11,19^{*}$ \\
CV $(\%)$ & 1,40 & 1,32 \\
\hline
\end{tabular}

"Dados originais; médias seguidas de mesma letra não diferem estatisticamente, pelo teste de Tukey, ao nível de 5\% de probabilidade. 


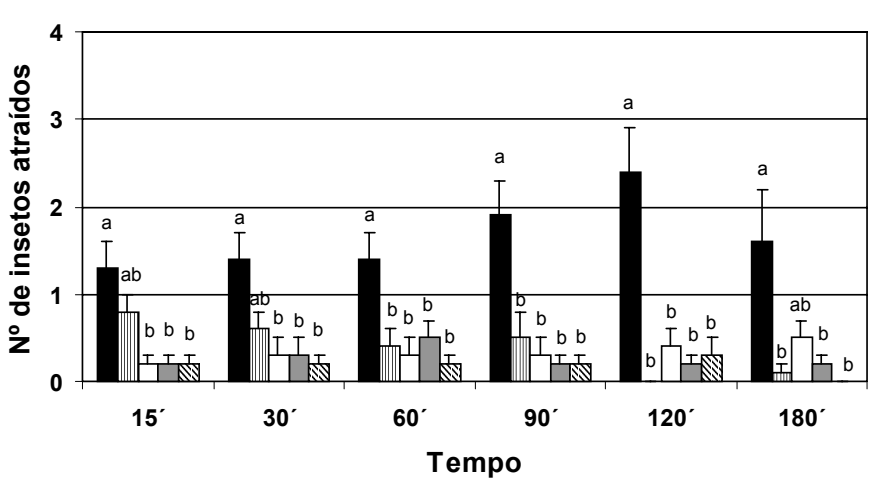

P. setacea $\mathbb{D}$. edulis $\square P$. alata $\square P$. nitida $\mathbb{Q}$. giberti

FIGURA 1 - Número médio original $( \pm$ EP) de adultos de Epicauta atomaria atraídos por discos foliares de espécies de maracujazeiro em placas de Petri. Colunas seguidas de mesma letra, dentro de cada período de observação, não diferem entre si, pelo teste de Tukey, a 5\% de probabilidade.

Ensaio com Olfatômetro. A atratividade em olfatômetro (Figura 2) mostra que 1 minuto após a liberação dos compartimentos, os extratos foliares de $P$. setacea, $P$. edulis $\mathrm{f}$. flavicarpa e $P$. alata foram mais atrativos, diferindo significativamente de $P$. nitida que não atraiu nenhum indivíduo. A baixa atratividade em discos foliares de $P$. nitida já havia sido relatada por Boiça Jr. et al. (1996); entretanto, no presente estudo, avaliou-se a atratividade dos extratos foliares em olfatômetro, o que torna os resultados mais precisos neste tipo de avaliação. A partir de 5 minutos da liberação dos compartimentos, notou-se não mais haver diferença estatística entre os extratos, podendose, porém, constatar que o extrato foliar de $P$. setacea foi ligeiramente mais atrativo, sobretudo a 45 e 60 minutos, confirmando os resultados observados na Tabela 1 e Figura 1 . O fato de os insetos estarem presentes dentro do olfatômetro já há 5 minutos antes da liberação dos compartimentos, pode ser uma possível explicação para a constatação de diferença estatística entre os extratos somente após 1 minuto da liberação. Isto sugere que, neste ambiente, talvez não seja necessário deixá-los por mais tempo para detectar-se a atração de E. atomaria.

Os elevados níveis de não-preferência para alimentação obseravdos em $P$. nitida e $P$. giberti, principalmente em teste de consumo sem chance de escolha, sugerem que talvez essas espécies não sejam hospedeiras naturais do inseto. Já com relação a $P$. edulis f. flavicarpa e $P$. alata, o fato de também terem apresentado não-preferência para alimentação vem questinar a indicação de E. atomaria como praga de espécies comerciais de maracujazeiro.

\section{CONCLUSÕES}

1) As folhas de $P$. setacea são altamente suscetíveis ao ataque do inseto.

2) As espécies $P$. nitida e $P$. giberti são resistentes a $E$. atomaria, expressando não-preferência para alimentação (atratividade e consumo).

3) As espécies $P$. edulis f. flavicarpa e P. alata apresentam não-

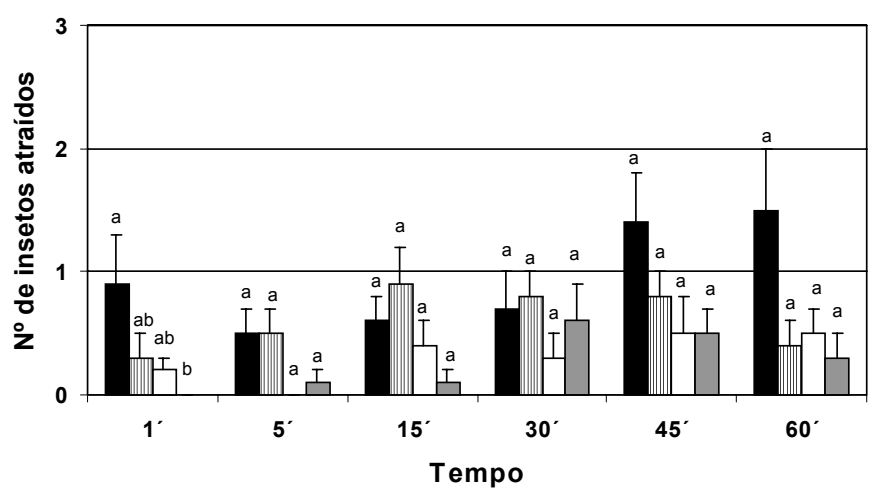

$P$. setacea 四P. edulis $\square P$. alata $\square$ P. nitida

FIGURA 2 - Número médio original (EP) de adultos de Epicauta atomaria atraídos por extratos de folhas de espécies de maracujazeiro em olfatômetro. Colunas seguidas de mesma letra, dentro de cada período de observação, não diferem entre si, pelo teste de Tukey, a 5\% de probabilidade.

preferência para alimentação em níveis mais baixos.

\section{REFERÊNCIAS BIBLIOGRÁFICAS}

BOARETTO, M. A. C.; BRANDÃO, A. L. S.; SÃO JOSÉ, A. R. Pragas do maracujazeiro. In: SÃO JOSÉ, A. R. (Ed.), Maracujá: produção e mercado. Vitória da Conquista: DFZ/UESB, 1994, p.99107.

BOIÇA JR., A. L.; LARA, F. M.; OLIVEIRA, J. C., PESSOA, R. Resistência de genótipos de maracujá a Epicauta atomaria (Germar, 1821)(Coleoptera: Meloidae)-Não-preferência alimentar. Boletin de Sanidad Vegetal Plagas, Madrid, v. 22, n. 1, p. 189192, 1996.

BOIÇA JR., A. L. Pragas da cultura do maracujazeiro. In: SIMPÓSIO BRASILEIRO SOBRE A CULTURA DO MARACUJAZEIRO, 1. Jaboticabal, 1998. Anais...Jaboticabal: FUNEP, 1998. p.175-203.

GALLO, D., NAKANO, O.;SILVEIRA NETO, S.;CARVALHO, R. P. L.;BATISTA, G. C. de, BERTI FILHO, E., PARRA, J. R. P.; ZUCCHI, R. A.; ALVES, S. B.; VENDRAMIM, J. D. Manual de entomologia agrícola. São Paulo: Ceres, 1988. 649p.

LARA, F. M. Princípios de resistência de plantas a insetos. São Paulo: Ícone, 1991.336p.

LOURENÇÃO, A. L.; OLIVEIRA, V. P. de; BOAVENTURA, M. A. M.;OLIVEIRA, V. P. de;MILAN-BOAVENTURA, M. A. Danos de adultos de Epicauta atomaria (Germar, 1821) em plantas de farinha-seca. Bragantia, Campinas, v. 44, n. 1, p. 437-440, 1985.

NASCIMENTO, W. A. O cultivo do maracujá. Goiânia: Empresa de Assistência Técnica e Extensão Rural do Estado de Goiás, 1997. 57p. (Boletim Técnico, 1). 
NEAD, B. A.; WEISS, M. J.; MILBRATH, L. R. Feeding preference of the ashgray blister beetle, Epicauta fabricini (Leconte) (Coleoptera: Meloidae) for four legumes. Canadian Entomologist, Fargo, v. 128, n. 2, p. 349-350, 1996.

ROSSETTO, C. J.; NAGAI, V.;IGUe, T., ROSSETtO, D.;MIRANDA, M. A. C. Preferência de alimentação de adultos de Diabrotica speciosa (Germar) e Cerotoma arcuata (Oliv.) em variedades de soja. Bragantia, Campinas, v. 40, n. 1, p. 179-183, 1981.

RUGGIERO, C.; SÃO JOSÉ, A. R.; VOLPE, C. A.; OLIVEIRA, J.
C., DURIGAN, J. F., BAUMGARTNER, J. G.; SILVA, J. R.; NAKAMURA, K.; FERREIRA, M. E.; KAVATI, R.; PEREIRA, V. P. Maracujá para exportação: aspectos técnicos da produção. Brasília: Embrapa-SPI, 1996. 64p. (Frupex, 19).

SANTOS, Z. F. D. F.; COSTA, J. M. Pragas da cultura do maracujá no Estado da Bahia. Salvador: Empresa de Pesquisa Agropecuária da Bahia S/A, 1983. 28p. (Circular Técnica, 4).

TEIXEIRA, C. G. Maracujá: cultura. In: ITAL. Maracujá: cultura, matéria-prima, processamento e aspectos econômicos. Campinas, 1994. p. 1-142. 